University of Nebraska - Lincoln

DigitalCommons@University of Nebraska - Lincoln

Faculty Publications, College of Journalism \& Journalism and Mass Communications, College Mass Communications

Fall 10-5-2018

\title{
Comparing Virtual Reality Tourism to Real-Life Experience: Effects of Presence and Engagement on Attitude and Enjoyment
}

\author{
Adam Wagler \\ University of Nebraska-Lincoln, adamwagler@unl.edu \\ Michael D. Hanus \\ University of Nebraska-Lincoln, mhanus2@unl.edu
}

Follow this and additional works at: https://digitalcommons.unl.edu/journalismfacpub

Part of the Broadcast and Video Studies Commons, Communication Technology and New Media Commons, Journalism Studies Commons, Mass Communication Commons, Public Relations and Advertising Commons, and the Social Influence and Political Communication Commons

Wagler, Adam and Hanus, Michael D., "Comparing Virtual Reality Tourism to Real-Life Experience: Effects of Presence and Engagement on Attitude and Enjoyment" (2018). Faculty Publications, College of Journalism \& Mass Communications. 121.

https://digitalcommons.unl.edu/journalismfacpub/121

This Article is brought to you for free and open access by the Journalism and Mass Communications, College of at DigitalCommons@University of Nebraska - Lincoln. It has been accepted for inclusion in Faculty Publications, College of Journalism \& Mass Communications by an authorized administrator of DigitalCommons@University of Nebraska - Lincoln. 


\title{
Comparing Virtual Reality Tourism to Real-Life Experience: Effects of Presence and Engagement on Attitude and Enjoyment
}

\author{
Adam Wagler ${ }^{1} \&$ Michael D. Hanus ${ }^{2}$ \\ 1 Assistant Professor, University of Nebraska-Lincoln \\ 2 Assistant Professor, The Ohio State University \\ Correspondence - Adam Wagler, College of Journalism and Mass Communications, \\ University of Nebraska-Lincoln, 331 Andersen Hall, Lincoln, NE 68588-0443; \\ email awagler2@unl.edu
}

ORCID Adam Wagler http://orcid.org/oooo-0003-2333-6036

\begin{abstract}
With the advent of 360-degree video technology, Virtual reality (VR) headsets can take users to locations in the real world. Despite the increasing number of virtual tourism opportunities using digital VR technology, little research has assessed the effective realism of 360-degree video tourism. This study took users on a guided audio tour of a state Capitol building. Users either took the tour via two-dimensional (2-D) video, immersive 360-degree video using a VR headset, or physically went to the location and walked around the grounds. Users were measured on spatial presence, emotional engagement with the tour, sponsor liking, and tour outreach intentions. Results indicate that users in the two-dimensional viewing condition scored low on all measures relative to the other conditions but that individuals in the physically present and 360-degree video condition had no differences between them. This suggests that 360 -degree video tourism may be a strong analogue to a real-world experience.
\end{abstract}

Keywords: Presence, Virtual Reality, Virtual Tourism

Published in Communication Research Reports Vol. 35, No. 5, 2018, pp. 456-464

DOI: $10.1080 / 08824096.2018 .1525350$

Copyright (c) 2018 Eastern Communication Association; published by Routledge/Taylor \& Francis Group. Used by permission.

Published 5 October 2018. 
Tn 2016, Google made it possible to explore national parks in the 1 United States via 360-degree virtual tours. Virtual reality (VR) headsets bring users to constructed, digital worlds, but the increasing use of 36o-degree video gives users the opportunity to visit real places through the headset, giving users new opportunities for digital entertainment and learning. Viewing real-world locations through a VR headset combines the benefits of realism with the customized and personal affordances of interactive media. To date, little research has been done directly comparing an immersive, 360-degree video experience with being physically present in the real-world location. By comparing traditional two-dimensional (2-D) media with immersive 360-degree video and real-world experiences, we can better understand how users experience virtual reality tours compared to the real thing.

Research indicates that virtual reality experiences mimic offline experiences better than traditional media or imagination (Ahn, Bailenson, \& Park, 2014). Research using VR headsets typically place participants within a digital, virtual world created for the purposes of the experiment (Ahn et al., 2015; Slater, Spanlang, Sanchez-Vives, \& Blanke, 2010). In contrast, 36o-degree video takes users to a real location that is filmed rather than digitally constructed. This study would be one of the first to look at high-resolution 36o-degree video footage using real-world environments, which is a closer analogue to real-world physical experiences.

It is not clear how a 360-degree virtual tour will match up against being physically present at the location. On the one hand, physical presence allows for the most realistic and detailed experience; users experience the tour with all the senses and must pay strong attention to the environment to navigate. Yet physical presence also may create negative user experiences and additional distractions due to bad weather, loud cars, or being jostled in a crowd. On the other hand, immersive 36o-degree videos' controlled environment can help minimize distractions or negative experiences, but it requires the user to balance being in two locations at once (i.e., in the room with the headset and in the location of the virtual tour). Virtual tourism opens up the possibility to visit protected (e.g., historical) or impossible to visit (e.g., outer space) sites. Furthermore, it creates the opportunity to make locations more accessible for those with physical impairments 
by visiting virtually. This increased access can improve user perceptions of the location, resulting in audiences being more accepting of the virtual experience as a substitute for the real location (Guttentag, 2010).

The extent to which users engage with a virtual reality tour may be dependent on their sense of presence or the feeling of being there (Barfield, Zeltzer, Sheridan, \& Slater, 1995; Lee, 2004). A strong sense of presence can be beneficial: Presence perceptions predict video game replay value (Roth, Vermeulen, Vorderer, \& Klimmt, 2012) and show less resistance to difficult messages (Burrows \& Blanton, 2016). Presence has been measured across multiple dimensions, including spatial, sensory, and social (ISPR 2000). Because we are measuring individuals in a virtual reality space compared with a physical one, we will limit our focus to spatial presence (i.e., the sense that one is in another place that can be navigated). Individuals with high spatial presence scores may show more emotional engagement with the medium and positive attitudes toward content within that medium from the sense of being there. Despite the detailed, realistic capabilities of an immersive 36o-degree video experience, we anticipate that:

H1: Those physically present will have higher spatial presence ratings compared to those experiencing a 36o-degree video, who will have higher ratings than viewing a two-dimensional space.

It is less clear how the different tour experiences will affect emotional engagement, the extent to which one is focused on content cognitively and affectively (Mollen \& Wilson, 2009). It is not clear how the benefits and drawbacks of physical presence compared with the benefits and drawbacks of a 360-degree video or two-dimensional experience will affect emotional engagement (e.g., will the distractions of the physical environment reduce emotional engagement more than the limited sensory input of a 360-degree video?).

RQ: How do virtual tours (two-dimensional or 36o-degree video) compare with physical presence on emotional engagement? 
The extent to which one likes the content and is focused (i.e., emotionally engaged) should in turn affect how much participants like the tour's sponsor and their willingness to speak to others about the tour. We predict an indirect effect of tour experience on sponsor liking and tour outreach intentions. Taking a tour via real-world experience, through a 360-degree headset, or through a two-dimensional screen will affect individuals' perceptions of spatial presence, which will increase their sense of emotional engagement, leading to increased sponsor liking and increased tour outreach intentions.

H2: Viewing conditions will have an indirect effect on sponsor likings and tour outreach intentions via spatial presence and emotional engagement.

\section{Method}

\section{Design}

This study implemented a three (two-dimensional video, 360-degree video, physically present) condition between-subjects design. Participants were randomly assigned to view a guided audio tour in one of the three conditions. Following the tour, spatial presence, emotional engagement, tour outreach intentions, and sponsor liking were measured.

\section{Sample}

Participants ( $N=116 ; 35$ men and 81 women $)$ were recruited from a Midwestern university in exchange for course credit. The sample ranged in age from 19 to $38(M=20.47, S D=2.87)$ and reported race/ ethnicity as Caucasian/European American/ White $(n=96)$; Asian/ Asian-American $(n=9)$; Black/African/African American $(n=4)$; Latino/Latina/Hispanic $(n=6)$; and Pacific Islander $(n=1)$.

\section{Procedure}

Participants were randomly assigned to condition. All participants were told that the State had contracted with the university to create 
a guided audio tour of the state capitol building. Participants were asked to test a shortened pilot version of the tour and then give their impressions of the tour in a survey afterward. Participants in the two-dimensional condition $(n=40)$ viewed the video on a computer screen, those in the 36o-degree video condition $(n=41)$ viewed the video through an Oculus Rift virtual reality headset, and those in the physically present condition $(n=36)$ went to the capitol building and walked around it.

All participants were provided with headphones and given instructions about the tour. Those in the physically present condition were given instructions on where to walk and told to return to the researchers at the conclusion of the tour. Following the conclusion of the tour, participants were given an online survey that assessed their spatial presence, emotional engagement, tour outreach intentions, and sponsor liking.

\section{Materials}

\section{Tour script and audio}

The 5-minute-long script was developed by the researchers to feature several facts about the state capitol building. The script designated three stopping points to present information; this ensured that participants would not need to shift focus between walking and listening to the tour. The script also included two mentions of a fictional tourism commission that "sponsored" the tour. These mentions occurred at the beginning and conclusion of the script.

\section{Two-dimensional video}

The two-dimensional video was filmed using a Canon 7D DSLR camera. The camera was positioned to look at the capitol building at the three designated stops and was pointed toward the sidewalk during the walking portions. Users viewed the full-screened twodimensional video on monitors in a computer lab provided by the researchers.

\section{6o-degree video}

The 360-degree video was filmed using a GoPro Omni 6 camera spherical 360 video rig. This featured stops at each of the three designated points and displayed the walk to each point. The researchers 
stitched and edited the video using Autopano Kolor. Participants viewed the video using the Oculus Rift virtual reality headset. Participants were seated during viewing but had the ability to turn their head to look in any direction during the tour.

\section{Measures}

\section{Spatial presence}

Participants were given a five-item spatial presence subscale adapted from Fredricks, Blumenfeld, and Paris (2004). These items $(M=4.96, S D=1.36, \alpha=.88)$ were measured on a scale ranging from 1 (not at all) to 7 (very strongly) and included questions such as "To what extent did you feel like you were outside the capitol building?" and "To what extent did you feel surrounded by the environment (e.g., cars, grass, air)?”

\section{Emotional engagement}

Seven items $(M=4.88, S D=1.15, \alpha=.89)$ adapted from Kim and Biocca (1997) were measured on a scale ranging from 1 (strongly disagree) to 7 (strongly agree) and included statements such as "The tour held my interest," and "I enjoyed the tour."

\section{Tour outreach intentions}

Three items $(M=4.42, S D=1.55, \alpha=.90)$ were measured on a scale ranging from 1 (strongly disagree) to 7 (strongly agree) and included statements such as "I would recommend this tour to others" and "I would post about this tour on social media."

\section{Sponsor liking}

Attitudes toward the fictional tourism commission were measured via five statements $(M=4.88, S D=1.02, \alpha=.86)$ that participants answered on a scale ranging from 1 (strongly disagree) to 7 (strongly agree) and included statements such as "I like the Tourism Commission" and "I think the Tourism Commission sounds like a good department.”

\section{Covariates}

Five covariates were measured: the number of years participants had lived in the state $(M=13.47, S D=8.30)$; whether participants had 
previously been on a tour of the inside of the capitol building (50.4\% reported yes; all public-schooled fourth graders in the state travel to the Capitol for a tour); the extent to which participants paid attention to the audio tour $(M=4.85, S D=1.43)$; whether participants believed the audio was easy to understand $(M=5 \cdot 37, S D=1.33)$; and whether they were interested in history $(M=4.68, S D=1.80)$.

A chi-square test was run to determine whether participants who had been on previous indoor capitol tours were distributed evenly across condition. Results indicate that there was no statistically significant association with previous tour experience and condition, $\chi(1)$ $=1.52, p=.468, \phi=.11$.

\section{Results}

To assess $\mathrm{H} 1$ and RQ, an ANCOVA was run among two-dimensional, 36o-degree video, and physically present conditions. Interest in history, years in the state, previous tour experience, the extent to which participants paid attention, and whether the tour was easy to understand were entered as covariates. ${ }^{1}$ Results indicate significant differences between groups for spatial presence and emotional engagement (Table 1). For each measure, those in the two-dimensional viewing condition scored lower, while those in the 360-degree video and physically present condition had no significant difference between their scores, showing partial support for $\mathrm{H} 1$ and answering the research question.

$\mathrm{H} 2$ predicted a serial mediation wherein viewing condition would indirectly affect tour outreach intentions and sponsor liking through spatial presence and emotional engagement. To address this hypothesis, a serial mediation was run using PROCESS Model 6 (Hayes, 2013).

Table 1 ANCOVA Results for Tour Condition

\begin{tabular}{lllllll} 
& & & & $2-D$ & 360 & Physical \\
\cline { 6 - 7 } & $F(1,116)$ & $p$ & partial $\eta^{2}$ & $M(S D)$ & $M(S D)$ & $M(S D)$ \\
\hline Spatial presence & 38.75 & $<.001$ & .42 & $3.78(1.32)^{\mathrm{a}}$ & $5.51(.94)^{\mathrm{b}}$ & $5.63(.89)^{\mathrm{b}}$ \\
Emotional engagement & 21.08 & $<.001$ & .28 & $4.06(1.19)^{\mathrm{a}}$ & $5.08(.92)^{\mathrm{b}}$ & $5.58(.74)^{\mathrm{b}}$ \\
\hline
\end{tabular}

Superscripts denote post hoc $t$-test comparisons using Bonferroni correction. Varying letters indicate a significant difference below $p=.05$. 
As a categorical variable, viewing condition was dummy coded. This coding scheme allows a multicategorical variable to be assessed as a dichotomous variable by comparing two groups while controlling for the effects of the third. For any given test, all groups were compared with each other: two-dimensional to 36o-degree video, 360-degree video to physically present, and two-dimensional to physically present. In any given comparison, the third condition group is entered as a covariate.

The serial mediation was run using the dummy coded condition variable as the independent variable, spatial presence as the first mediator, emotional engagement as the second mediator, and tour outreach intentions (and sponsor liking in a second test) as the outcome variable. Interest in history, years in the state, previous tour experience, the extent to which participants paid attention, and whether the tour was easy to understand were entered as covariates. ${ }^{2}$ Results indicate that both the 360-degree video and physically present conditions show an indirect effect relative to the two-dimensional condition (Table 2). Compared to the two-dimensional participants, individuals in the 36o-degree video or physically present conditions reported higher spatial presence scores, which increased emotional engagement and ultimately led to increases in tour outreach intentions and sponsor liking (Figure 1 ).

\section{Discussion}

This research examined the ways a 360-degree virtual experience can compare to real life by measuring spatial presence, emotional engagement, tour outreach intentions, and sponsor liking. Our results indicated that both real-world and immersive 360-degree video tours

Table 2 Indirect Effect of Tour Condition on Tour Outreach Intentions and Sponsor Liking

\begin{tabular}{|c|c|c|c|c|c|c|c|c|c|}
\hline & \multicolumn{3}{|c|}{$2-D / 360$} & \multicolumn{3}{|c|}{ 36o/Physical } & \multicolumn{3}{|c|}{ 2-D/Physical } \\
\hline & $\begin{array}{c}\text { Indirect } \\
\text { Effect }\end{array}$ & $S E$ & $95 \% C I$ & $\begin{array}{c}\text { Indirect } \\
\text { Effect }\end{array}$ & $S E$ & $95 \% C I$ & $\begin{array}{c}\text { Indirect } \\
\text { Effect }\end{array}$ & $S E$ & $95 \% C I$ \\
\hline Tour outreach intentions & -.59 & .16 & {$[-.95,-.33]^{*}$} & .06 & .08 & {$[-.06, .25]$} & -.52 & .14 & {$[-.83,-.30]^{*}$} \\
\hline Sponsor liking & .15 & .08 & {$[.03, .37]^{*}$} & .03 & .03 & {$[-.03, .11]$} & -.22 & .07 & {$[-.40,-.11]^{*}$} \\
\hline
\end{tabular}

* $95 \%$ confidence interval that does not include zero, indicating an indirect effect. 

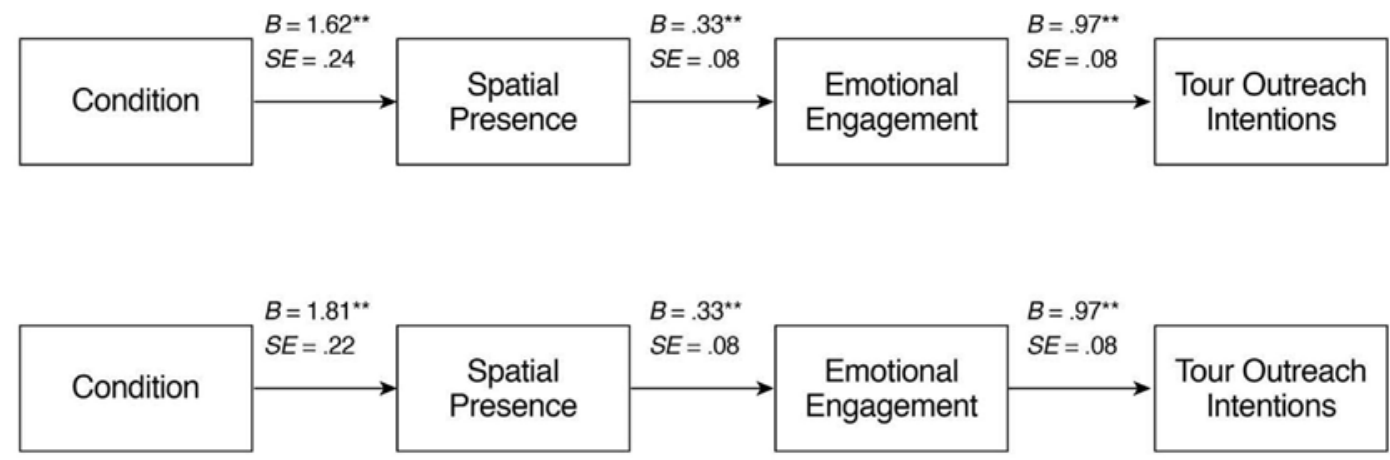

Figure 1 Beta coefficients for comparison between physically present and twodimensional (top) and 36o- degree video experience and two-dimensional viewing (bottom).

scored equally on all measures, answering the research question and establishing that 360-degree video experiences are viewed very similarly to real-world experiences. Results also indicate an indirect effect of viewing condition on tour outreach intentions and sponsor liking through increased spatial presence followed by increased emotional engagement.

Limitations of this study include the sample and the location of the experience. The sample was comprised of college students and cannot be applied to broader demographics. However, new media platforms and emerging technology skew toward younger adopters (Nielsen, 2016). The physically present condition was conducted during a threeweek window during the month of November. While the temperature never dropped below 40 degrees Fahrenheit, it is possible that the weather conditions affected participants' enjoyment of the experience. It was not reported as a problem during data collection, but this represents a potential confound that future research should address.

Theoretically, this study replicates the connection between spatial presence and emotional engagement and establishes a mechanism by which a virtual experience can affect one's attitudes and affect. Results indicate a new potentially interesting avenue for digital entertainment. Immersive media that allows users to remotely visit 36o-degree filmed locations of parks, concerts, sporting events, or news stories could open doors for those unable to attend in person but still feel present and engaged with the content. These findings have practical applications for entertainment industries, suggesting that people 
might be able to have fulfilling, engaging experiences from the comfort of their own home. Further, this work has application in education and distance-learning outcomes, wherein students could use virtual tours to engage in otherwise cost-prohibitive learning opportunities.

Disclosure No potential conflict of interest was reported by the authors.

\section{Notes}

1. All variables were tested without covariates and revealed significant differences between condition: spatial presence, $F(1,116)=37.14, p<.001$, partial $\eta^{2}=.40$ and emotional engagement, $\mathrm{F}(1,116)=23.41, \mathrm{p}<.001$, partial $\eta^{2}=.30$.

2. Serial mediation comparisons for both tour outreach intentions and sponsor liking were also run without covariates and likewise indicated significant indirect effects for each.

\section{References}

Ahn, S. J., Bailenson, J., \& Park, D. (2014). Short and long-term effects of embodied experiences in immersive virtual environments on environmental locus of control and behavior. Computers in Human Behavior, 39, 235-245. doi:10.1016/j.chb.2014.07.025

Ahn, S. J., Bostick, J., Ogle, E., Nowak, K., McGillicuddy, K., \& Bailenson, J. (2015). Experiencing nature: Embodying animals in immersive virtual environments increases inclusion of nature in self and involvement with nature. Journal of Computer-Mediated Communication, 21, 1-21.

Barfield, W., Zeltzer, D., Sheridan, \& Slater, T. (1995). Presence and performance within virtual environments. Virtual Environments and Advanced Environment Design, eds. W. Barfield and T. A. Furness. New York: Oxford University Press.

Burrows, C., \& Blanton, H. (2016). Real-world persuasion from virtualworld campaigns: How transportation into virtual worlds moderates in-game influence. Communication Research, 43(4), 542-570. doi:10.1177/0093650215619215

Fredricks, J., Blumenfeld, P., \& Paris, A. (2004). School engagement: Potential of the concept, state of the evidence. Review of Educational Research, 74(1), 59109. doi:10.3102/00346543074001059

Guttentag, D. A. (2010). Virtual reality: Applications and implications for tourism. Tourism Management, 31(5), 637-651. doi:10.1016/j.tourman.2009.07.003 Communication Research Reports 463 
Hayes, A. F. (2013). Methodology in the social sciences. In Introduction to mediation, moderation, and conditional process analysis: A regression-based approach. New York, NY: Guilford Press.

International Society for Presence Research. (2000). The concept of presence: Explication statement. Retrieved from https://ispr.info/

Kim, T., \& Biocca, F. (1997). Telepresence via television: Two dimensions of telepresence may have different connections to memory and persuasion. Journal of Computer-Mediated Communication, 3(2). Retrieved from https:// doi.org/10.1111/j.1083-6101.1997.tboo073.x

Lee, K. M. (2004). Presence, explicated. Communication Theory, 14(1), 27-50. doi:10.1111/comt.2004.14.issue-1

Mollen, A., \& Wilson, H. (2009). Engagement, telepresence, and interactivity in online consumer experience: Reconciling scholastic and managerial perspectives. Journal of Business Research, 63, 909-925.

Nielsen. (2016, September 9). Reality check: A peek at the virtual audiences of tomorrow. Nielsen. com Retrieved March 1, 2017, from http://www.nielsen. com/us/en/insights/news/2016/reality-check-a-peek-at-the-virtual-audiencesof-tomorrow.html

Roth, C., Vermeulen, I., Vorderer, P., \& Klimmt, C. (2012). Exploring replay value: Shifts and continuities in user experiences between first and second exposure to an interactive story. Cyberpsychology, Behavior \& Social Networking, 15(7), 378-381. doi:10.1089/cyber.2011.0437

Slater, M., Spanlang, B., Sanchez-Vives, M., \& Blanke, O. (2010). First person experience of body transfer in virtual reality. PLoS One, 5(5). doi:10.1371/ journal.pone.0010564 